\title{
Laron Syndrome
}

National Cancer Institute

\section{Source}

National Cancer Institute. Laron Syndrome. NCI Thesaurus. Code C130994.

Growth hormone insensitivity syndrome caused by mutation(s) and/or deletion(s) in the GHR gene, encoding the growth hormone receptor. 